УДК 621.311.001.63 (035)

\title{
ОБОСНОВАНИЕ УСТАНОВКИ ПУНКТОВ РЕГУЛИРОВАНИЯ НАПРЯЖЕНИЯ С ВОЛЬТДОБАВОЧНЫМИ ТРАНСФОРМАТОРАМИ В ЛИНИЯХ ЭЛЕКТРОПЕРЕДАЧ 0,4-10(6) КВ
}

\section{Андрианова Людмила Прокопьевна \\ д-р техн. наук, профессор \\ Рябишина Лилия Амировна \\ канд. техн. наук, доцент \\ Хуртов Владислав Евгеньевич}

Уфимский государственный нефтяной технический университет

Аннотация. В статье представлены технико-экономические расчеты, обосновывающие возможность установки в протяженных линиях электропередач (ЛЭП) 0,4-10(6) кВ пунктов регулирования напряжения (ПНР) с вольтдобавочными трансформаторами (ВДТ), обеспечивающих снижение потерь напряжения в узлах сети и нормативные показатели качества электроэнергии у потребителей. При реконструкции ЛЭП рассматривается вариант увеличения сечения провода линии, а в качестве альтернативы установка ВДТ. Для нового строительства рассматривается вариант строительства двухцепной воздушной линии 35 кВ с подстанцией 35/10 кВ, а в качестве альтернативы - строительство одной или двух ЛЭП 6-10 кВ с установкой ПРН из трех ВДТ для обеспечения нормального уровня напряжения в часы максимума нагрузок. Определены капитальные затраты на реализацию всех вариантов реконструкции и нового строительства. На основе сравнительного анализа капитальных затрат всех вариантов показана целесообразность установки ВДТ и ПРН, как мероприятие с наименьшими финансовыми затратами.

Ключевые слова: Линия электропередачи, распределение напряжения, качество электроэнергии, жалобы потребителей, предписания надзорных органов, вольтдобавочные трансформаторы, пункты регулирования напряжения, наименьшие капитальные затраты. 


\title{
JUSTIFICATION FOR THE INSTALLATION OF VOLTAGE CONTROL POINTS WITH VOLTAGE-ADD-ON TRANSFORMERS IN POWER LINES OF 0,4-10 (6) KV
}

\section{Andrianova Lyudmila Prokopyevna Ryabishina Lilia Amirovna Hurtov Vladislav Evgenievich}

\begin{abstract}
The article presents technical and economic calculations that justify the possibility of installing in extended power lines (power lines) of 0.4-10(6) $\mathrm{kV}$ voltage control points (PNR) with voltage-add-on transformers (VDT), which reduce voltage losses in the network nodes and standard indicators of the quality of electricity for consumers. When reconstructing power lines, the option of increasing the cross-section of the line wire is considered, and as an alternative, the installation of VDT. For the new construction, the option of building a $35 \mathrm{kV}$ double-chain overhead line with a $35 / 10 \mathrm{kV}$ substation is considered, and as an alternative, the construction of one or two $6-10 \mathrm{kV}$ power lines with the installation of a PRN of three VDT to ensure a normal voltage level during peak load hours. The capital costs for the implementation of all options for reconstruction and new construction are determined. Based on a comparative analysis of the capital costs of all options, the feasibility of installing VDT and PRN with the lowest financial costs is shown.
\end{abstract}

Key words: Power transmission line, voltage distribution, quality of electricity, consumer complaints, regulations of supervisory authorities, voltage-addon transformers, voltage regulation points, lowest capital costs.

Установка вольтодобавочных трансформаторов (ВДТ) [1, с. 3] с автоматическим регулированием напряжения в распределительных сетях 6-20 0,4 кВ позволяет оперативно реагировать на жалобы потребителей на низкое качество электроэнергии, не соответствующее требованиям ГОСТ 321442013[6], в частности по таким показателям, как «Отклонение напряжения» и «Несимметрия напряжения», определяемых по результатам контроля и мониторинга по ГОСТ 33073-2014 [7].

Для обеспечения требуемого качества напряжения в протяженных распределительных сетях 6-20 - 0,4 кВ сетях рекомендуется проводить 
корректирующие мероприятия с установкой ВДТ или пунктов регулирования напряжения (ПРН) [5, с. 218].

Для подтверждения целесообразности установки ВДТ или ПРН в соответствии с требованиями нормативных документов необходимо рассмотреть альтернативные варианты корректирующих мероприятий, провести технико-экономическое сравнение, на основе которого следует выбрать вариант с наименьшими капитальными затратами [2] .

Необходимость установки ВДТ обосновывается, если имеются жалобы потребителей на качество электрической энергии и предписания надзорных органов об устранении этих нарушений [2].

В статье приводятся типовые примеры технико-экономического обоснования установки ВДТ в ЛЭП 10/0,4 кВ (при реконструкции) и ПРН в электрических сетях 10 кВ с центром питания от подстанции ПС-35/10 кВ (при новом строительстве) $[1,3]$.

Технико-экономическое сравнение вариантов реконструкции ЛЭП приведено на примере расчетной схемы (рис. 1) с параметрами, указанными в таблице 1. Для проведения реконструкции ЛЭП предложены два варианта.

1-й вариант: Реконструкция воздушной линии (ВЛ) с заменой провода AC-50 на провод марки АC-95 для уменьшения потерь напряжения.

Таблица 1

Исходные данные для расчета [2]

\begin{tabular}{|l|c|}
\hline Однолинейная схема ЛЭП & 10 кВ \\
\hline Длина линии по магистрали & 29,5 км \\
\hline Напряжение в начале узла & 10,5 кВ \\
\hline Коэффициент мощности & 0,92 \\
\hline $\begin{array}{l}\text { Максимальный ток в начале линии с учетом } \\
\text { присоединения дополнительной нагрузки }\end{array}$ & 65 А \\
\hline
\end{tabular}




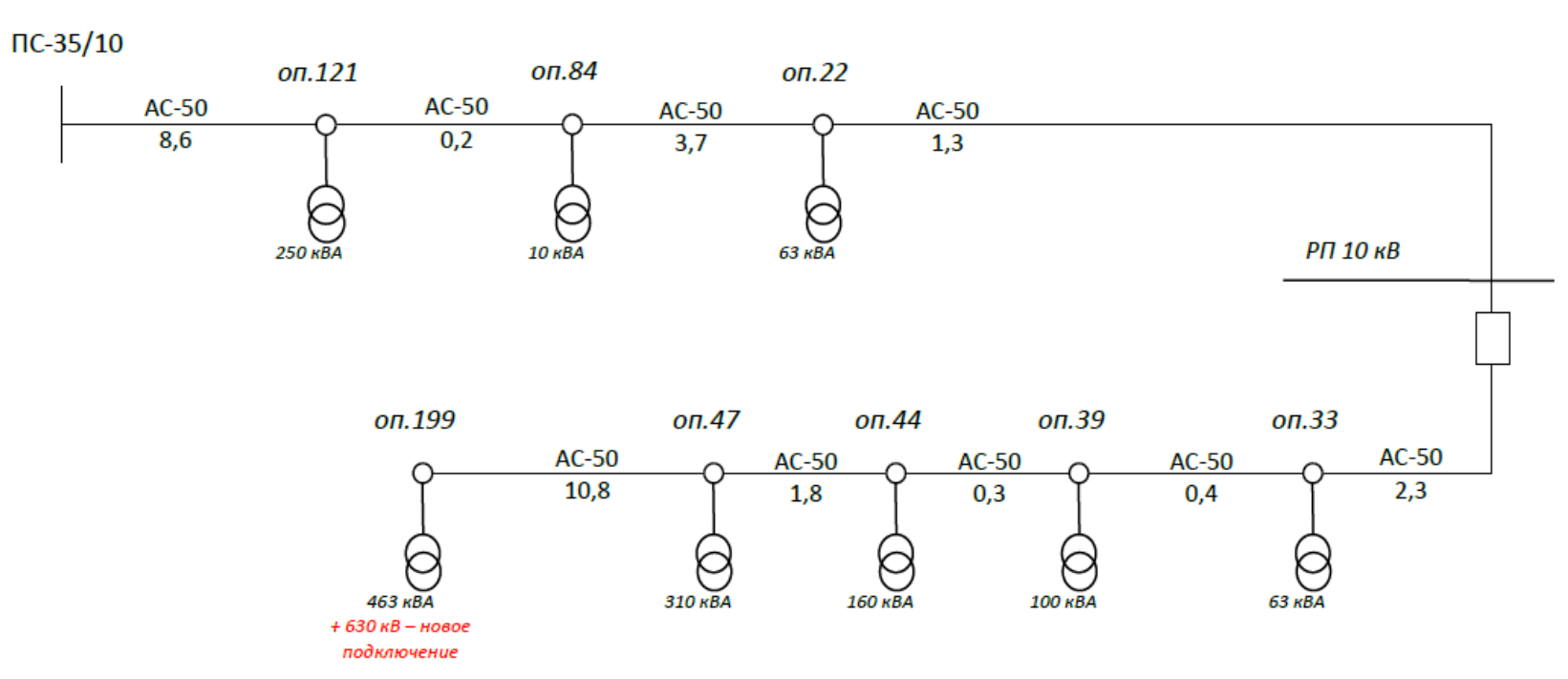

Рис. 1. Расчетная схема ЛЭП [2]

Таблица 2

Затраты на реконструкцию ВЛ с заменой провода на марку АС-95 (1-й вариант реконструкции ЛЭП)

\begin{tabular}{|c|c|c|c|c|}
\hline $\begin{array}{l}\text { № } \\
\Pi / \Pi\end{array}$ & $\begin{array}{l}\text { Виды работ и } \\
\text { оборудования }\end{array}$ & Расценка & $\begin{array}{c}\text { Общая } \\
\text { стоимость, } \\
\text { тыс. руб. }\end{array}$ & $\begin{array}{c}\text { Общая стоимость с } \\
\text { учетом } \\
\text { регионального } \\
\text { коэффициента } \\
\text { тыс. руб. }\end{array}$ \\
\hline 1 & $\begin{array}{l}\text { Строительно- } \\
\text { монтажные работы } \\
\text { без опор и провода }\end{array}$ & $\begin{array}{c}\text { Расценка } \\
\text { Л1-02-1: } \\
767 \text { тыс. руб. /км }\end{array}$ & 22626 & $\begin{array}{c}22626 \times 0,73=16 \\
517\end{array}$ \\
\hline 2 & Стоимость опор & $\begin{array}{c}\text { Расценка } \\
\text { Л3-02-1: } \\
699 \text { тыс. руб./ км }\end{array}$ & 20620 & $\begin{array}{c}20620 \times 0,73=15 \\
053\end{array}$ \\
\hline 3 & $\begin{array}{l}\text { Стоимость провода } \\
\text { трех фаз длиной } \\
29,5 \text { км }\end{array}$ & $\begin{array}{l}\text { Расценка Л5-02: } \\
431 \text { тыс. руб./км }\end{array}$ & 12714 & $12714 \times 0,73=9281$ \\
\hline 4 & $\begin{array}{l}\text { Стоимость } \\
\text { проектных работ }\end{array}$ & $\begin{array}{l}\text { Расценка П3-04: } \\
2319 \text { тыс. руб. }\end{array}$ & 2319 & $2319 \times 0,73=1693$ \\
\hline 5 & \multicolumn{2}{|c|}{$\begin{array}{l}\text { Суммарная стоимость реконструкции } \\
29,5 \text { км ВЛ (без НДС) }\end{array}$} & 58279 & 42544 \\
\hline
\end{tabular}


Затраты на реконструкцию ВЛ с заменой провода АС 50 на марку АС-95 оценены в соответствии с Приказом Министерства энергетики РФ «Об утверждении укрупненных нормативов цены типовых технологических решений капитального строительства объектов электроэнергетики» [4] и приведены в таблице 2 .

Как следует из таблицы 2, суммарная стоимость реконструкции ВЛ протяженностью 29,5 км типового проекта составляет 58279 тыс. руб. , а с учетом регионального коэффициента составляет 42544 тыс. руб.

$\kappa_{\text {рег. }}=0,73$ для региона Башкортостан определен по таблице $[4$, таблица 2]

2-й вариант: Установка пункта регулирования напряжения (ПРН) из двух ВДТ 10 кВ с номинальным током 100 А, с диапазоном регулирования \pm 10 $\%$.

Предлагаемое место установки - в районе опоры 22.

Затраты на установку ПРН с двумя вольтодобавочными трансформаторами приведены в таблице 3 .

Таблица 3

Затраты на ПРН-10У1 с двумя вольтодобавочными трансформаторами (2-й вариант реконструкции ЛЭП)

\begin{tabular}{|c|l|c|}
\hline $\begin{array}{c}\text { № } \\
\text { п/п }\end{array}$ & \multicolumn{1}{|c|}{ Виды работ и оборудования } & \multicolumn{1}{c|}{$\begin{array}{c}\text { Общая стоимость, } \\
\text { тыс. руб. }\end{array}$} \\
\hline 1 & $\begin{array}{l}\text { Пункт регулирования напряжения } \\
\text { ПРН-10У1 из двух вольтодобавочных } \\
\text { трансформаторов 10 кВ } \\
\text { номинальным током 100 А (без НДС) }\end{array}$ & 4000 \\
\hline 2 & $\begin{array}{l}\text { Проектно-изыскательские работы } \\
\text { (ПИР) и строительно-монтажные } \\
\text { работы (СМР) }\end{array}$ \\
\hline 3 & Суммарная стоимость (без НДС) & 2000 \\
\hline
\end{tabular}

Капитальные вложения а установку ПРН-10У1 составляют 6000 тыс. руб., т. е. значительно меньше по сравнению с 1-м вариантом реконструкции при замене на провод большего сечения.

Распределение напряжения на ВЛ 10 кВ в существующей ЛЭП, и по вариантам реконструкции показано на рис. 2. 


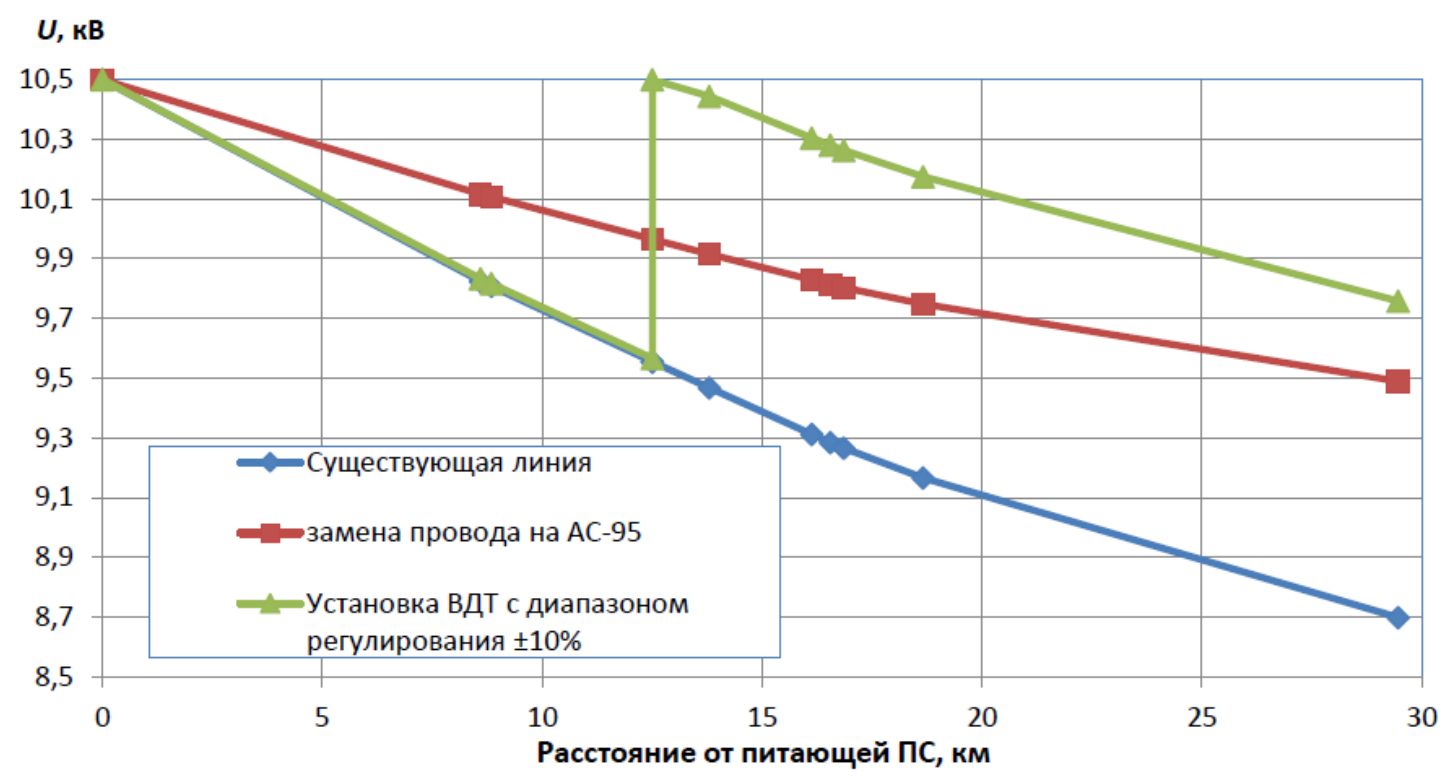

\section{Рис. 2. Распределение напряжения на ВЛ 10 кВ в существующей ЛЭП и по вариантам реконструкции ЛЭП [2]}

Вывод по вариантам реконструкции ЛЭП. Установка ПРН-10У1 с двумя ВТД экономически целесообразна по сравнению с 1-м вариантом реконструкции ЛЭП путем замены провода АС 50 на марку АС-95.

В примере нового строительства ЛЭП для технико-экономического сравнения рассматриваются два варианта обеспечения электроснабжения потребителя.

В первом варианте рассматривается строительство двухцепной ВЛ 35 кВ проводом АС-95 и ПС 35/10 кВ, мощностью $2 \times 4$ MBA и установка на существующей ПС 110/35/10 кВ двух ячеек с трехфазными выключателями 35 кВ для подключения новых линий 35 кВ, как показано на рис. 3.

При строительстве двухцепной ВЛ 35 кВ и ПС 35/10 кВ были приняты следующие исходные данные:

- существующая подстанция с двумя трансформаторами Т1 и Т2 (ПС 110/35/10 кВ 2×16 МВА) имеет резерв не менее 4 МВ·A;

- требуется подключение потребителя с максимальной мощностью 3,5 МВт, коэффициент мощности 0,95 от двух линий;

- расстояние от подстанции ПС 110 кВ до потребителя - 15 км. 


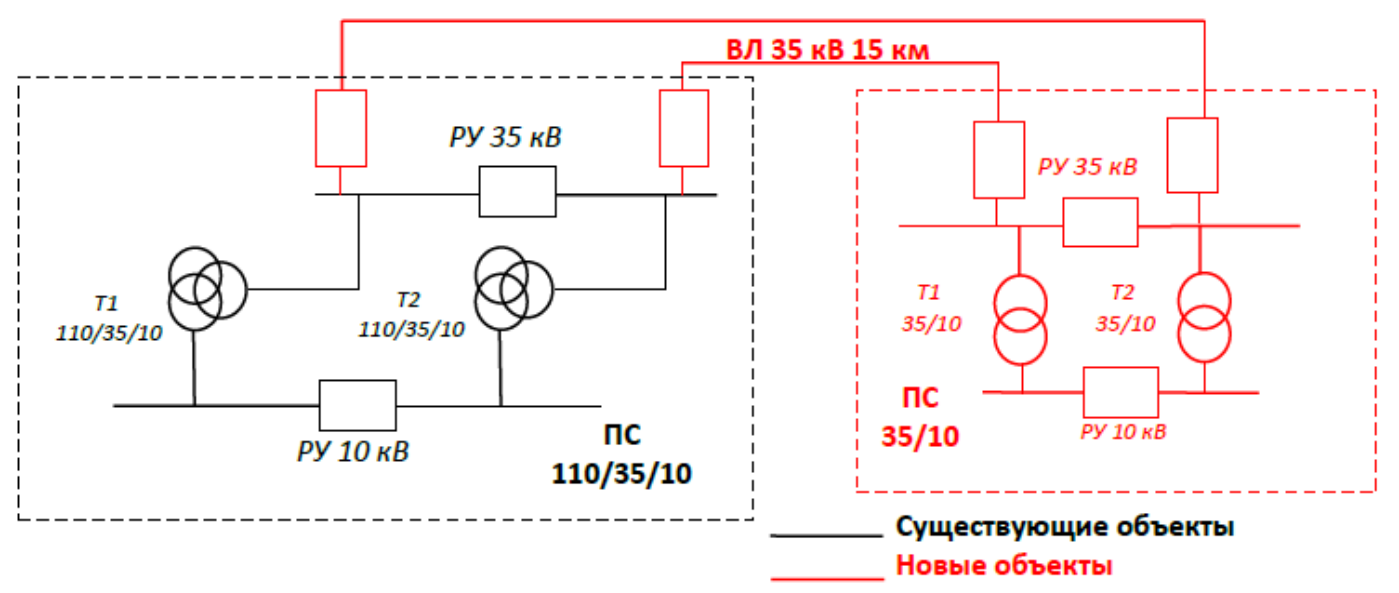

\section{Рис. 3. Строительство двухцепной ВЛ 35 кВ проводом АС-95 и ПС 35/10 кВ (1-й вариант) [1, 5 ]}

Затраты на строительство двухцепной воздушной линии ВЛ 35 кВ и подстанции ПС $35 / 10$ кВ рассчитаны в соответствии со Приказом Министерства энергетики РФ «Об утверждении укрупненных нормативов цены типовых технологических решений капитального строительства объектов электроэнергетики» [4] и приведены в таблице 4.

Суммарные затраты по 1-му варианту нового строительства двухцепной ВЛ 35 кВ и ПС 35/10 кВ составили 163907 тыс. руб.

Во втором варианте нового строительства рассматривается строительство двух ВЛ 10 кВ с установкой ПРН 300 А 10 кВ из трех ВДТ с диапазоном регулирования $\pm 15 \%$ (рис. 4).

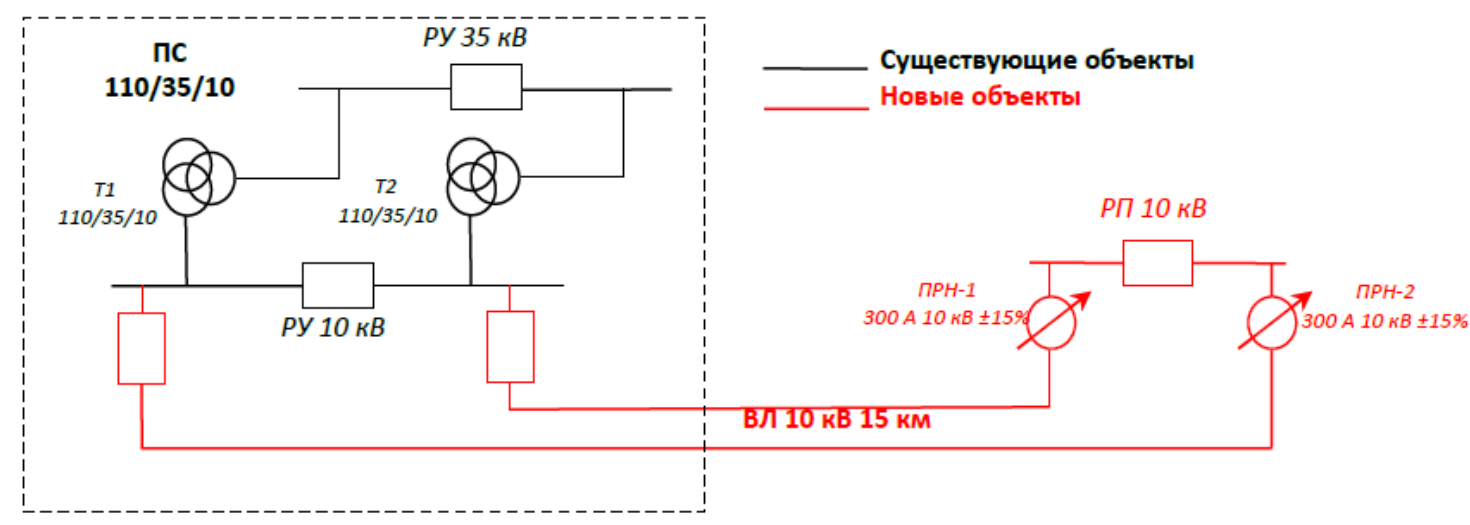

Рис. 4. Строительство двух ВЛ 10 кВ с установкой ПРН 300 А 10 кВ из трех ВДТ (2-й вариант) [1, 5] 
Таблица 4

Затраты на строительство двухцепной ВЛ 35 кВ проводом АС-95 и ПС 35/10 кВ (1-й вариант нового строительства )

\begin{tabular}{|c|c|c|c|}
\hline $\begin{array}{l}\text { № } \\
\text { ПI/II }\end{array}$ & Виды работ и оборудования & Расценка & Общая стоимость \\
\hline 1 & $\begin{array}{l}\text { Стоимость строительства двух } \\
\text { дополнительных ячеек } 35 \text { кВ на } \\
\text { существующей ПС } 110 / 35 / 10 \text { кВ }\end{array}$ & $\begin{array}{l}\text { Расценка В2-05-1: } \\
9040 \text { тыс. руб./яч. }\end{array}$ & 18080 тыс. руб. \\
\hline 2 & \multicolumn{3}{|c|}{ Строительство 15 км двухцепной ВЛ 35 кВ: } \\
\hline 3 & $\begin{array}{l}\text { a) Строительно-монтажные } \\
\text { работы без опор и провода }\end{array}$ & $\begin{array}{l}\text { Расценка Л1-03-2: } \\
2997 \text { тыс. руб./км }\end{array}$ & 44955 тыс. руб. \\
\hline 4 & б) Стоимость опор & $\begin{array}{l}\text { Расценка Л3-03-3: } \\
\qquad 2 \\
270 \text { тыс. руб. / км }\end{array}$ & 34050 тыс. руб. \\
\hline 5 & $\begin{array}{l}\text { в) Стоимость провода шести фаз } \\
\text { длиной } 15 \text { км }\end{array}$ & $\begin{array}{l}\text { Расценка Л5-02 } \\
431 \text { тыс. руб./км }\end{array}$ & 12930 тыс. руб. \\
\hline 6 & $\begin{array}{l}\text { г) Стоимость проектно- } \\
\text { изыскательских работ для ВЛ } \\
35 \text { кВ }\end{array}$ & $\begin{array}{c}\text { Расценка П3-08: } \\
6270 \text { тыс. руб. }\end{array}$ & 6270 тыс. руб. \\
\hline 7 & \multicolumn{3}{|c|}{ Строительство подстанции 35/10 кВ: } \\
\hline 8 & $\begin{array}{l}\text { a) Строительство трех ячеек } 35 \\
\text { кВ }\end{array}$ & $\begin{array}{c}\text { Расценка В2-05-1: } 9040 \\
\text { тыс. руб./яч. }\end{array}$ & 27120 тыс. руб. \\
\hline 9 & $\begin{array}{l}\text { Стоимость двух } \\
\text { трансформаторов 4MBA 35/10 } \\
\text { кВ }\end{array}$ & $\begin{array}{c}\text { Расценка Т4-03-1: } 12 \\
906 \text { тыс. руб. }\end{array}$ & 25812 тыс. руб. \\
\hline 10 & $\begin{array}{l}\text { в) Стоимость постоянной части } \\
\text { ПС } 35 \text { кВ }\end{array}$ & $\begin{array}{l}\text { Расценка 31-01: } \\
31011 \text { тыс. руб. }\end{array}$ & \\
\hline 11 & $\begin{array}{l}\text { г) Проектно-изыскательские } \\
\text { работы ПС } 35 \text { кВ }\end{array}$ & $\begin{array}{c}\text { Расценка П1-01: } \\
7235 \text { тыс. руб. }\end{array}$ & 7235 тыс. руб. \\
\hline 12 & \multicolumn{2}{|l|}{ Общие затраты по 1-му варианту } & 163907 тыс. руб. \\
\hline
\end{tabular}

При проведении технико-экономическом сравнения по второму варианту нового строительства затраты на сооружение распределительного пункта РП 10 кВ не учитывались (таблица 5). 
Таблица 5

\section{Затраты на строительство двух ВЛ 10 кВ с установкой ПРН 300 А 10 кВ из трех ВДТ (2-й вариант )}

\begin{tabular}{|c|c|c|c|}
\hline $\begin{array}{l}\text { № } \\
\text { ПI/ா }\end{array}$ & Виды работ и оборудования & Расценка & Общая стоимость \\
\hline 1 & $\begin{array}{l}\text { Дополнительные ячейки } 10 \text { кВ } \\
\text { на существующей ПС 110/35/10 } \\
\text { кВ }\end{array}$ & $\begin{array}{l}\text { Расценка В2-01-1: } \\
2486 \text { тыс. руб./яч. }\end{array}$ & 4972 тыс. руб. \\
\hline 2 & \multicolumn{3}{|c|}{ Строительство 15 км двух одноцепных ВЛ 10 кВ: } \\
\hline 3 & $\begin{array}{l}\text { a) Строительно-монтажные } \\
\text { работы без опор и провода }\end{array}$ & $\begin{array}{l}\text { Расценка Л1-02-1: } \\
767 \text { тыс. руб. / км }\end{array}$ & 23010 тыс. руб. \\
\hline 4 & б) Стоимость опор & $\begin{array}{l}\text { Расценка Л3-02-1: } \\
699 \text { тыс. руб. / км }\end{array}$ & 20970 тыс. руб. \\
\hline 5 & в) Стоимость провода & $\begin{array}{l}\text { Расценка Л5-02: } \\
431 \text { тыс. руб./км. }\end{array}$ & 12930 тыс. руб. \\
\hline 6 & $\begin{array}{l}\text { г) Стоимость проектно- } \\
\text { изыскательских работ для ВЛ } 10 \\
\text { кВ }\end{array}$ & $\begin{array}{l}\text { Расценка П3-08: } \\
2319 \text { тыс. руб. }\end{array}$ & 2319 тыс. руб. \\
\hline 7 & \multicolumn{3}{|c|}{ Стоимость двух ПРН 10 кВ номинальным током 300 А из трех ВДТ: } \\
\hline 8 & $\begin{array}{l}\text { a) Стоимость одной единицы } \\
\text { оборудования }\end{array}$ & 8000 тыс. руб. & 16000 тыс. руб. \\
\hline 9 & $\begin{array}{l}\text { б) Стоимость проектно- } \\
\text { изыскательских и строительно- } \\
\text { монтажных работ на установку } \\
\text { ПРН }\end{array}$ & 4000 тыс. руб. & 4000 тыс. руб. \\
\hline 10 & \multicolumn{2}{|l|}{ Общие затраты по 2-му варианту } & 84201 тыс. руб. \\
\hline
\end{tabular}

Вывод по новому строительству: Строительство ЛЭП 10 кВ с установкой ПРН на каждой линии ВЛ 10 кВ экономически более целесообразно, т.к. капитальные затраты меньше на 79706 тыс. руб., чем при строительстве двухцепной ВЛ 35 кВ и ПС 35/10 кВ.

\section{Список литературы}

1. Вольтодобавочные трансформаторы. Общие технические требования : СТО 34.01-3.2-013-2017. Стандарт организации ПАО «Россети», введ. 02.08.2017. - 43 c. // www.rosseti.ru. - Режим доступа 12.03.2021.

2. Методические указания по применению вольтодобавочных трансформаторов (пунктов регулирования напряжения) 6-20 кВ и вольтодобавочных трансформаторов 0,4 кB $\quad$ в линиях электропередачи 
распределительных сетей. Том 1.1. Методические указания : СТО 34.01-3.2.17014.1-2020. Стандарт организации ПАО «Россети», введ. 04.03.2020. - 44 с. //www.rosseti.ru. - Режим доступа 12.03.2021.

3. Методические указания по применению вольтодобавочных трансформаторов (пунктов регулирования напряжения) 6-20 КВ и вольтодобавочных трансформаторов 0,4 КВ в линиях электропередачи распределительных сетей. Том 1.2. Типовые решения : СТО 34.01-3.2.17-014.22020. Стандарт организации ПАО «Россети», введ. 04.03.2020. - 44 с. //www.rosseti.ru. - Режим доступа 12.03.2021.

4. Об утверждении укрупненных нормативов цены типовых технологических решений капитального строительства объектов электроэнергетики в части объектов электросетевого хозяйства. Министерство энергетики Российской Федерации. Приказ от 17 января 2019 года N 10. - 66с. // http://docs.cntd.ru/document/552209237 . - Режим доступа 11.03.2021.

5. Распределительные электрические сети напряжением 0,4-110 кВ. Требования к технологическому проектированию: СТО 34.01-21.1-001-2017. Стандарт организации ПАО «Россети», введ. 02.08.2017. - 238 с. // www.rosseti.ru. - Режим доступа 12.03.2021.

6. Электрическая энергия. Совместимость технических средств электромагнитная. Нормы качества электрической энергии в системах электроснабжения общего назначения: ГОСТ 32144-2013. Межгосударственный стандарт. - Введ. 01.07. 2014. - Москва: Стандартинформ, 2014. - 20 с.

7. Электрическая энергия. Совместимость технических средств электромагнитная. Контроль и мониторинг качества электрической энергии в системах электроснабжения общего назначения: ГОСТ 33073-2014. Межгосударственный стандарт. - Введ. 01.01. 2015. - Москва: Стандартинформ, 2015. - 45 с.

(C) Андрианова Л.П., Рябишина Л.А., В.Е. Хуртов, 2021 